Bull. Chem. Soc. Ethiop. 2019, 33(1), 91-102.

ISSN 1011-3924

(C) 2019 Chemical Society of Ethiopia and The Authors

Printed in Ethiopia

DOI: https://dx.doi.org/10.4314/bcse.v33i1.9

\title{
COMPUTATIONAL STUDIES ON HETEROGENIZATION OF HOMOGENEOUS CATALYST OF IRON(III), NICKEL(II) AND COPPER(II) N,N'-DISALICYLIDENE- 1,2-PHENYLENEDIAMINE COMPLEX
}

\author{
Solomon Legese Hailu ${ }^{1,2^{*}}$, Balachandran Unni Nair ${ }^{2}$, Mesfin Redi-Abshiro ${ }^{1}$, Isabel Diaz ${ }^{1,3}$ and \\ Merid Tessema ${ }^{1}$ \\ ${ }^{1}$ Department of Chemistry, Addis Ababa University, P.O. Box 1176, Addis Ababa, Ethiopia \\ ${ }^{2}$ Chemical Laboratory, CSIR-Central Leather Research Institute, Adyar, Chennai 600 020, India \\ ${ }^{3}$ Instituto de Catálisis y Petroleoquímica, ICP-CSIC, C/Marie Curie 2, 28049 Cantoblanco, \\ Madrid, Spain
}

(Received March 17, 2018; Revised September 28, 2018; Accepted December 24, 2018)

\begin{abstract}
Density functional theory (DFT) calculations were carried out on iron(III), nickel(II) and copper(II) complexes of $\mathrm{N}, \mathrm{N}^{\prime}$-ethylenebis(salicylimine) both at molecular level (isolated complexes) and encapsulated in a zeolite framework to investigate changes that occur in their geometrical and electronic parameters as well as in their reactivity and stability. The computational results showed that the zeolite encapsulated metal complexes have higher reactivity and less stability as compared to the isolated metal complexes.
\end{abstract}

KEY WORDS: Density functional theory, $\mathrm{N}, \mathrm{N}^{\prime}$-ethylenebis(salicylimine), Computational studies, Heterogenization, Electronic parameters

\section{INTRODUCTION}

The catalyst is used for many industrial and related activities like food, chemical, environment, medicine, etc. Owing to its different applications of catalyst synthesis or upgrading of the existed catalytic system is the hot research area. The present catalyst system is classified into homogeneous and heterogeneous based on the phase of the components of the reaction in which it is acting [1]. Transition metal-based complexes and organometallic compounds are examples of homogeneous catalysts. These catalysts are soluble in the reaction medium and are used in the production of different chemicals.

The transition metal-based homogeneous catalyst is a well-known catalytic system for different industrial applications. The effectiveness of the homogeneous catalyst is attributed to change in oxidation state of the central metal ion and the coordination environment of the ligand [2]. Unlike to homogeneous catalysts, transition metal-based heterogeneous catalysts are normally solid species attached to an inorganic or organic solid surface [3-5].

Since the beginning of the twentieth century, both homogeneous and heterogeneous catalysts have been extensively used for the industrial applications. Though, the industrial applications of heterogeneous catalysis have grown at a faster rate than homogeneous catalysis [6]. The problem associated with less interest in the homogeneous catalytic system is the difficulty of separation of catalysts from reaction medium and active site deactivation due to self-aggregation of the catalyst $[3,6,7]$. Therefore, applying of heterogenization process on the homogeneous catalytic system could bring the advantages of both homogeneous and heterogeneous systems $[8,9]$. The term heterogenization implies the process of immobilization of homogeneous transition metal complexes by attaching with a supporting medium [10-12]. Several materials that can be employed for supporting homogeneous catalysts include zeolites, Nafion film or Nafion pallet, polyethylene copolymers, silica fabrics and clay etc [13-15]. The unique characteristics of inorganic supporting materials linked to its flexibility and stability

*Corresponding author. E-mail: birllpti.2001@gmail.com

This work is licensed under the Creative Commons Attribution 4.0 International License 
made them a good supporting or hosting medium. Among the above inorganic hosting materials, zeolites are attractive microporous supporting materials for the immobilization or encapsulation of transition metal complexes or organometallics within their cavities because it is cheap, naturally abundant and unique properties [16-18]. These include ion exchange abilities and a rigid three-dimensional crystalline structure consisting of a network of interconnected tunnels and cages [19-21].

The main problem in the preparation of zeolite encapsulated metal complexes is to identify suitable conditions at which well-defined distribution of transition metal complex happened in the zeolite cage, in its place of being concentrated on the zeolite external surface. Additionally, the encapsulation of metal complexes into zeolite cage helps to combine the characteristics of both neat zeolite and metal complex to obtain new hybrid catalysts [22]. Therefore, a comprehensive characterization of synthesized catalyst as compared to the neat metal complex and neat zeolite is necessary to ensure encapsulation process is properly established. The information we could able to extract from the existing physicochemical characterization techniques is limited. In general, zeolite encapsulated metal complexes are characterized to address the following aspects; the composition of metal complexes residing in the zeolite cage; the framework of zeolite is preserved after the encapsulation of metal complexes; thermal stability of the encapsulated metal complexes as compared to neat metal complexes and neat zeolite; morphological changes associated with encapsulation process; effect of molecular confinement on the conformational geometry and the mobility of the complexes inside the zeolite cage; internal versus external confinement and the distribution of guest compounds in zeolite host; nature of the metal complex formed in zeolite cavity compared to neat metal complex and neat zeolite; the effect of host-guest interactions on the structure of metal complex [22-24].

The existing physicochemical characterization techniques do not provide full information about the stability, reactivity, and proper inclusion of metal complex inside the zeolite cage. Furthermore, it is not possible to have the information about the influence of the zeolite matrix on the structure and electronic properties of the enclosure compounds. However, a theoretical investigation of the physical and chemical properties based quantum chemical calculations has provided a better understanding of the properties of neat metal complex and zeolite encapsulated metal complexes and the science behind their catalytic activity and stability [22-26]. Quantum chemical calculation based on density functional theory (DFT) is one of the operational tools in explaining chemical reactivity of the catalyst [27-31]. DFT calculation is also applied to understand the change in structural or geometrical parameters through calculations of bond length, bond angle and torsional angle of neat and encapsulated metal complexes [32, 33]. Besides, the stability and reactivity of encapsulated complexes are investigated through highest occupied molecular orbitals (HOMO) and lowest unoccupied molecular orbitals (LUMO) energies of the metal complexes upon encapsulation into zeolite super cage [34, 35].

In this study, the geometrical and electronic properties of iron(III), nickel(II) and copper(II) $\mathrm{N}, \mathrm{N}^{\prime}$-disalicylidene-1,2-phenylenediamine based homogeneous and heterogeneous catalyst and the consequent effect of heterogenization of the homogeneous catalyst through encapsulation of metal complexes into the zeolite super cage was investigated. Moreover, the geometrical change, stability, and reactivity of transition metal based homogeneous and heterogeneous catalyst is associated with the change in the energies of HOMO and LUMO was also studied.

\section{COMPUTATIONAL DETAILS}

On this study, the computational calculation was investigated using the density functional theory (DFT) approaches. For electronic and geometrical optimizations, generalized gradient approximation (GGA) and Perdew-Burke-Ernzerhof (PBE) exchange functional correlation were used along with double numerical (DN) basis set as implemented in the Dmol ${ }^{3}$ program. The electronic density convergence threshold was set at $10^{-6}$ in the self-consistent field (SCF) 
calculations. The optimization of geometrical parameters was executed with maintaining the value convergence thresholds for energy, force and atomic shifts about $10^{-5} \mathrm{Ha}, 2 \times 10^{-3} \mathrm{Ha} / \AA$, and $10^{-3} \AA$, respectively. The electronic structure of homogeneous catalyst of $\mathrm{Fe}(\mathrm{III}), \mathrm{Ni}(\mathrm{II})$ and $\mathrm{Cu}(\mathrm{II})$-Salophen complex as well as its heterogeneous catalyst associated with zeolite $\mathrm{Y}$ encapsulated respective metal complexes was calculated.

Zeolite has well-defined three-dimensional rigid and stable structure having channels or cages which may be interconnected to form a multi-dimensional porous system of defined size [19-21], so that the encapsulation of $\mathrm{Fe}(\mathrm{III}), \mathrm{Ni}(\mathrm{II})$ and $\mathrm{Cu}(\mathrm{II})$-Salophen complexes in these zeolite Y cavities allows the variation of their geometrical condition in a systematic method. The geometrical optimization of zeolite $Y$ was investigated with fixing their super cage internal diameter and pore opening was about approximately $13.0 \AA$ and $7.4 \AA$, respectively. Since zeolite Y belongs to Faujasite family 48 tetrahedral units (48T) of the structure were used for a generation the given zeolite $\mathrm{Y}$ clusters with saturating them with hydrogen atoms. Each of the terminal $\mathrm{H}$ atoms was optimized were fixed the framework of $\mathrm{Si}$ and $\mathrm{O}$ atoms of the clusters at their crystallographic positions. The encapsulated transition metal complexes inside the zeolite cage were optimized in repeatedly. During the optimization, terminated hydrogen atoms in the zeolite clusters are held fixed at their originally optimized positions.

The DFT-Koopmans theorem was employed so as to calculate the change in chemical and electronic properties while heterogenization of the homogeneous catalyst of $\mathrm{Fe}(\mathrm{III}), \mathrm{Ni}(\mathrm{II})$, and $\mathrm{Cu}(\mathrm{II})-$ Salophen complexes using reactivity and stability parameters. The parameters of reactivity and stability such as global hardness $(\eta)$ and chemical potential $(\mu)$ of the neat metal complex and zeolite Y encapsulated metal complex were calculated with applying DFTKoopmans theorem using the presented Equation 1 and 2 [36];

$$
\begin{gathered}
\eta=\frac{E_{L U M O}-E_{H O M O}}{2} \\
\mu=\frac{E_{L U M O}+E_{H O M O}}{2}
\end{gathered}
$$

where $\mathrm{E}_{\mathrm{LUMO}}$ is represents energy of the lowest unoccupied molecular orbital and $\mathrm{E}_{\mathrm{HOMO}}$ is also shows the energy of highest occupied molecular orbital. DFT based global descriptors such as global electrophilicity $(\omega)$ and global softness (s) was also calculated according to Parr et al. as shown in Equation 3 and 4 [37];

$\omega=\frac{\mu^{2}}{2 \eta}$

$s=\frac{1}{2 \eta}$

\section{RESULTS AND DISCUSSION}

\section{DFT studies on neat zeolite $Y$}

Zeolite $\mathrm{Y}$ is made of $\mathrm{SiO}_{4}$ and $\mathrm{AlO}_{4}$ tetrahedra primary building blocks joined through oxygen bridges to form a three-dimensional structure having four or six-membered rings. The further interconnection of four- and six-membered rings also leads to the formation of the super cage. This super cage has a larger diameter among other cavities in the zeolite structure and it is the sole responsible for accepting the incoming transition metal complexes as a host. In accordance to this, the DFT calculation was used to create the optimized geometrical structure of the neat zeolite Y. Figure 1 shows the optimized DFT figure of neat zeolite $Y$ and as shown in the figure the super cage is successfully formed having $13 \AA$ and in the zeolite crystallographic T-site $(\mathrm{T}=$ $\mathrm{Si}$ or $\mathrm{Al}$ ) and every $\mathrm{Si}$ atom links four types of the geometrical oxygen atom. 

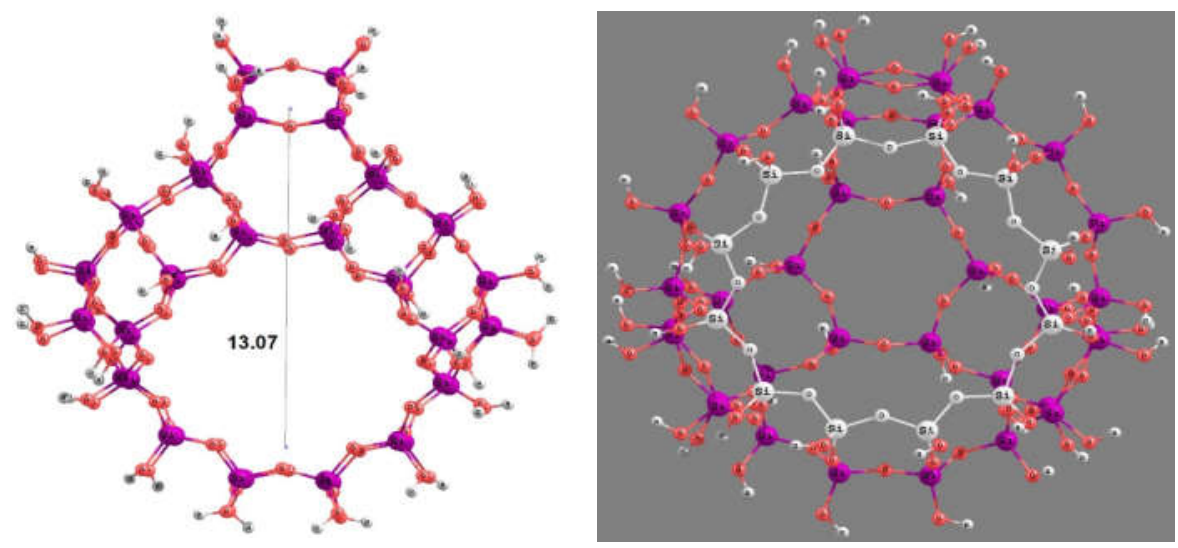

Figure 1. The DFT optimized figure of neat zeolite Y.

Geometrical optimization of metal complex and metal complex encapsulated into zeolite cage

Figure 2 shows the geometrical parameters obtained from Perdew-Burke-Ernzerhof (PBE) exchange functional correlation are used along with double numerical (DN) basis level calculations for the neat and encapsulated metal complexes. The neat Salophen complex of $\mathrm{Fe}(\mathrm{III}), \mathrm{Ni}(\mathrm{II})$ and $\mathrm{Cu}(\mathrm{II})$ DFT geometrical parameters of bond length was compared with that of zeolite Y encapsulated Fe(III), Ni(II) and Cu(II) Salophen complexes and it depicted in Table 1. The obtained optimized geometrical parameters of bond length difference of the neat and the encapsulated metal complex are relatively in good agreement. As observed from Table 1 and Figure 2 that the obtained average bond length differences between homogeneous catalyst of $\mathrm{Fe}(\mathrm{III}), \mathrm{Ni}(\mathrm{II})$ and $\mathrm{Cu}$ (II) Salophen complexes and heterogeneous catalyst of $\mathrm{Fe}(\mathrm{III}), \mathrm{Ni}$ (II) and $\mathrm{Cu}(\mathrm{II})$ Salophen complexes after optimization were $0.070,0.004$ and $0.014 \AA$, respectively. This is an indication of the successful formation of the same structural compounds of metal Salophen metal complexes inside the zeolite super cage as a heterogeneous catalyst. However, the slight bond length observed after encapsulation of for $\mathrm{Fe}(\mathrm{III}), \mathrm{Ni}$ (II) and $\mathrm{Cu}$ (II) Salophen complexes is attributed to the steric effect generated by the zeolite $\mathrm{Y}$ host material on the guest metal complexes.

Table 1. The optimized bond length (in $\AA$ ) for homogeneous and heterogeneous catalyst metal Salophen complexes, $(\mathrm{M}=\mathrm{Fe}(\mathrm{III}), \mathrm{Ni}(\mathrm{II})$ and $\mathrm{Cu}(\mathrm{II}))$.

\begin{tabular}{|c|c|c|c|c|c|c|}
\hline $\begin{array}{c}\text { Bond } \\
\text { type }\end{array}$ & $\begin{array}{c}\mathrm{Fe}(\mathrm{III})- \\
\text { Salophen } \\
\text { complex }\end{array}$ & $\begin{array}{c}\mathrm{Fe} \text { (III)-Salophen } \\
\text { complex in zeolite } \\
\text { Y cage }\end{array}$ & $\begin{array}{c}\text { Ni(II)-Salophen } \\
\text { complex }\end{array}$ & $\begin{array}{c}\text { Ni(II)-Salophen } \\
\text { complex in } \\
\text { zeolite Y cage }\end{array}$ & $\begin{array}{c}\text { Cu(II)- } \\
\text { Salophen } \\
\text { complex }\end{array}$ & $\begin{array}{c}\mathrm{Cu}(\mathrm{II})-\mathrm{Salophen} \\
\text { complex in } \\
\text { zeolite Y cage }\end{array}$ \\
\hline $\mathrm{N}_{1}-\mathrm{M}$ & 1.946 & 1.861 & 1.881 & 1.878 & 1.951 & 1.958 \\
\hline $\mathrm{N}_{2}-\mathrm{M}$ & 1.946 & 1.855 & 1.881 & 1.876 & 1.957 & 1.977 \\
\hline $\mathrm{O}_{1}-\mathrm{M}$ & 1.869 & 1.953 & 1.851 & 1.849 & 1.980 & 1.992 \\
\hline $\mathrm{O}_{2}-\mathrm{M}$ & 1.870 & 1.952 & 1.851 & 1.846 & 1.977 & 1.982 \\
\hline $\mathrm{Cl}-\mathrm{M}$ & 2.135 & 2.144 & - & - & 2.396 & 2.370 \\
\hline
\end{tabular}

$\mathrm{Cl}, \mathrm{N}_{1}, \mathrm{~N}_{2}, \mathrm{O}_{1}$ and $\mathrm{O}_{2}$ denotes the chlorine, nitrogen and oxygen atoms, respectively attached to the central metal ion $(\mathrm{M}=\mathrm{Fe}(\mathrm{III}), \mathrm{Ni}(\mathrm{II})$ and $\mathrm{Cu}(\mathrm{II}))$ in the Salophen complex.

Table 2 shows the optimized bond angle and torsional angle for $\mathrm{Fe}(\mathrm{III}), \mathrm{Ni}(\mathrm{II})$ and $\mathrm{Cu}(\mathrm{II})$ Salophen based complex of the homogeneous and heterogeneous catalyst. The results indicate that most of the optimized bond angles and torsional angle of neat metal complexes are slightly larger than the encapsulated one. This reveals that the guest $\mathrm{Fe}(\mathrm{III}), \mathrm{Ni}(\mathrm{II})$ and $\mathrm{Cu}$ (II) Salophen 
complexes are existed in the different geometrical atmosphere. As it is also observed from the table the average optimized bond length changes observed between homogeneous and heterogeneous metal complexes catalyst after optimization is about 1.0, 0.1925 and 1.69 degree for $\mathrm{Fe}(\mathrm{III}), \mathrm{Ni}(\mathrm{II})$ and $\mathrm{Cu}(\mathrm{II})$ Salophen complexes, respectively. The change in bond angle after encapsulation suggested that the metal complexes are successfully enclosed into the zeolite-Y

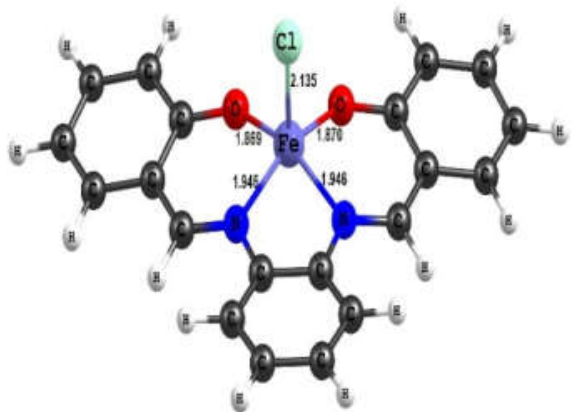

Fe(III)-Salophen complex

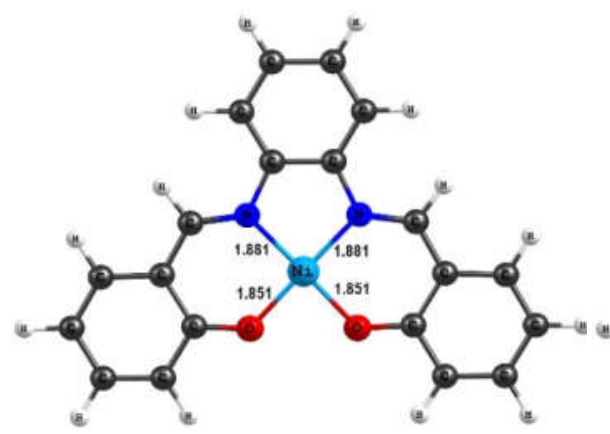

$\mathrm{Ni}(\mathrm{II})-$ Salophen complex

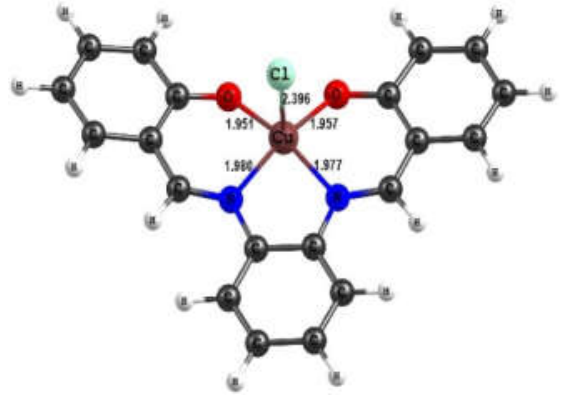

$\mathrm{Cu}(\mathrm{II})$-Salophen complex

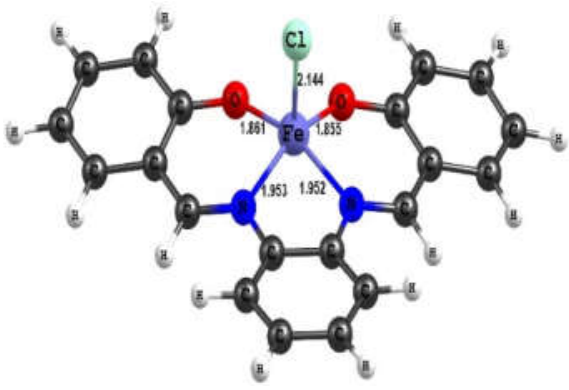

Fe(III)-Salophen complex in zeolite Y cage

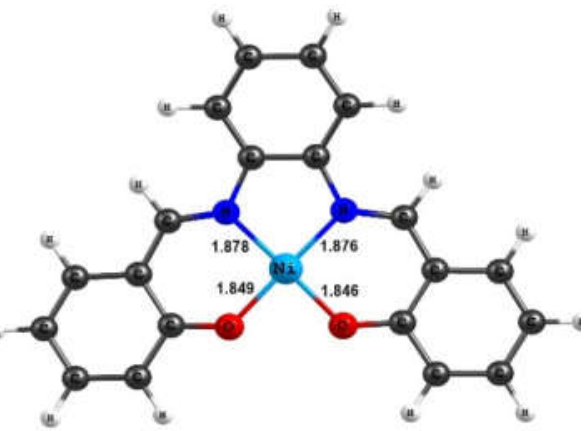

$\mathrm{Ni}(\mathrm{II})-$ Salophen complex in zeolite Y cage

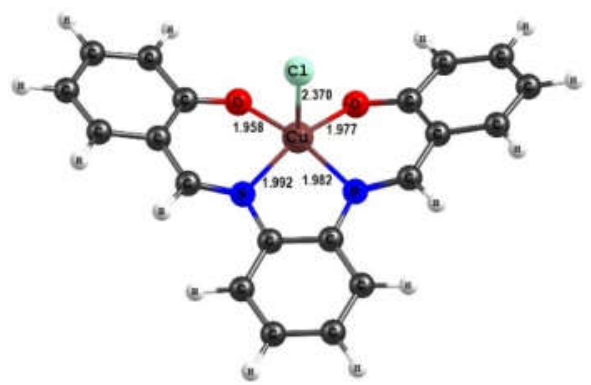

$\mathrm{Cu}(\mathrm{II})$-Salophen complex in zeolite Y cage

Figure 2. Schematic representation of bond length change for $\mathrm{Fe}(\mathrm{III}), \mathrm{Ni}(\mathrm{II})$ and $\mathrm{Cu}(\mathrm{II})-\mathrm{Salophen}$ based homogeneous and heterogeneous catalyst. 
cage. The bond angle, bond angle and torsional angle difference observed after encapsulation is associated with the existence of the metal complexes into different geometrical symmetry. The literature report shows that the primary building blocks of silicon and oxygen bonds in the zeolite structure have covalent character [27]. Therefore the change in geometrical properties observed after encapsulation is attributed to the influence of electron-electron repulsions between the metal complex and the nearby partially delocalized electrons in the zeolite cage.

Table 2. The optimized bond angles (in degree) and torsional angle (in degree) for metal-Salophen based homogeneous and heterogeneous catalyst, ( $\mathrm{M}=\mathrm{Fe}(\mathrm{III}), \mathrm{Ni}(\mathrm{II})$ and $\mathrm{Cu}(\mathrm{II})$ ).

\begin{tabular}{|c|c|c|c|c|c|c|c|}
\hline $\begin{array}{l}\text { Bond } \\
\text { type }\end{array}$ & $\begin{array}{l}\text { Fe(III)- } \\
\text { Salophen } \\
\text { complex }\end{array}$ & $\begin{array}{c}\mathrm{Fe}(\mathrm{III})-\text { Salophen } \\
\text { complex in } \\
\text { zeolite Y cage }\end{array}$ & $\begin{array}{l}\text { Ni(II)- } \\
\text { Salophen } \\
\text { complex }\end{array}$ & $\begin{array}{r}\mathrm{Ni}(\mathrm{I} \\
\mathrm{cc} \\
\mathrm{zed}\end{array}$ & $\begin{array}{l}\text { Salophen } \\
\text { lex in } \\
\text { Y cage }\end{array}$ & $\begin{array}{l}\mathrm{Cu}(\mathrm{II})- \\
\text { Salophen } \\
\text { complex }\end{array}$ & $\begin{array}{c}\mathrm{Cu}(\mathrm{II})-\mathrm{Salophen} \\
\text { complex in zeolite } \\
\text { Y cage }\end{array}$ \\
\hline \multicolumn{8}{|c|}{ Bond angle } \\
\hline $\mathrm{O}_{1}-\mathrm{M}-\mathrm{O}_{2}$ & 84.16 & 85.23 & 83.88 & \multicolumn{2}{|c|}{83.92} & 86.40 & 89.08 \\
\hline $\mathrm{O}_{2}-\mathrm{M}-\mathrm{N}_{2}$ & 92.14 & 91.72 & 94.74 & \multicolumn{2}{|c|}{94.72} & 92.82 & 90.20 \\
\hline $\mathrm{N}_{2}-\mathrm{M}-\mathrm{N}_{1}$ & 82.26 & 81.75 & 86.64 & \multicolumn{2}{|c|}{86.29} & 83.56 & 83.10 \\
\hline $\mathrm{N}_{1}-\mathrm{M}-\mathrm{O}_{1}$ & 92.15 & 92.26 & 94.74 & \multicolumn{2}{|c|}{95.10} & 91.82 & 91.56 \\
\hline $\mathrm{O}_{1}-\mathrm{M}-\mathrm{Cl}$ & 104.00 & 103.24 & - & \multicolumn{2}{|c|}{-} & 100.68 & 99.20 \\
\hline $\mathrm{O}_{2}-\mathrm{M}-\mathrm{Cl}$ & 104.11 & 106.69 & - & \multicolumn{2}{|c|}{-} & 102.59 & 101.68 \\
\hline $\mathrm{N}_{2}-\mathrm{M}-\mathrm{Cl}$ & 99.08 & 98.20 & - & \multicolumn{2}{|c|}{-} & 96.42 & 97.55 \\
\hline $\mathrm{N}_{1}-\mathrm{M}-\mathrm{Cl}$ & 99.10 & 97.43 & - & \multicolumn{2}{|c|}{-} & 95.10 & 99.08 \\
\hline \multicolumn{8}{|c|}{ Torsional angle } \\
\hline $\mathrm{C}-\mathrm{O}_{1}-\mathrm{M}-\mathrm{Cl}$ & -83.69 & \multicolumn{2}{|l|}{-80.74} & \multicolumn{2}{|c|}{-} & -67.36 & -68.31 \\
\hline $\mathrm{C}-\mathrm{O}_{1}-\mathrm{M}-\mathrm{N}_{2}$ & 91.45 & 90.59 & \multicolumn{2}{|c|}{-179.78} & 117.83 & 102.58 & 102.34 \\
\hline $\mathrm{C}-\mathrm{O}_{1}-\mathrm{M}-\mathrm{O}_{2}$ & 173.19 & \multirow{2}{*}{173.22} & \multicolumn{2}{|c|}{179.97} & 173.25 & -169.50 & -169.99 \\
\hline $\mathrm{C}-\mathrm{O}_{1}-\mathrm{M}-\mathrm{N}_{1}$ & 16.24 & & \multicolumn{2}{|c|}{-0.03} & -7.79 & 28.20 & 31.14 \\
\hline $\mathrm{C}-\mathrm{O}_{2}-\mathrm{M}-\mathrm{Cl}$ & 83.77 & 84.65 & \multicolumn{3}{|c|}{-} & 75.06 & 65.79 \\
\hline $\mathrm{C}-\mathrm{O}_{2}-\mathrm{M}-\mathrm{N}_{2}$ & -16.15 & -14.44 & & & 9.67 & -22.16 & -31.97 \\
\hline $\mathrm{C}-\mathrm{O}_{2}-\mathrm{M}-\mathrm{N}_{1}$ & -91.42 & -88.04 & -17 & 9.84 & 144.61 & -99.76 & -103.07 \\
\hline $\mathrm{C}-\mathrm{O}_{2}-\mathrm{M}-\mathrm{O}_{1}$ & -173.23 & -172.94 & -17 & 9.98 & -168.36 & 175.21 & 164.99 \\
\hline
\end{tabular}

$\mathrm{Cl}, \mathrm{N}_{1}, \mathrm{~N}_{2}, \mathrm{O}_{1}$ and $\mathrm{O}_{2}$ denotes chlorine, nitrogen and oxygen atoms, respectively linked to the metal ion $(\mathrm{M}=$ $\mathrm{Fe}(\mathrm{III}), \mathrm{Ni}(\mathrm{II})$ and $\mathrm{Cu}(\mathrm{II}))$ in the Salophen complex.

Optimization of metal complex and metal complex encapsulated into zeolite cage

The pattern and value of the highest occupied molecular orbital (HOMO) and the lowest unoccupied molecular orbital (LUMO) for homogeneous and heterogeneous catalyst are shown in Figures 3, 4 and 5 their energies are also given in Table 3. As observed from the figures and table the HOMO and LUMO energy of the zeolite encapsulated heterogeneous catalyst become destabilized and their energy increase in comparison to the homogeneous catalyst. The HOMOLUMO gap $\left(\Delta \mathrm{E}_{\mathrm{H}-\mathrm{L}}\right)$ of the heterogeneous catalyst of $\mathrm{Fe}(\mathrm{III}), \mathrm{Ni}(\mathrm{II})$ and $\mathrm{Cu}(\mathrm{II})$ Salophen complexes (Figures 3, 4 and 5) was found to decrease upon encapsulation. This suggests that transfer of electrons from the heterogeneous catalyst of $\mathrm{Fe}(\mathrm{III}), \mathrm{Ni}(\mathrm{II})$ and $\mathrm{Cu}$ (II) Salophen complexes encapsulated into the zeolite cage is much more feasible than respective neat complexes. It is plausible theoretical evidence behind the improvement of reactivity for the heterogeneous catalyst of metal complexes once they are encapsulated into the zeolite super cage. The authors of this article also reported somewhere else about the experimental evidence of the higher reactivity of heterogeneous catalyst of zeolite Y encapsulated iron(III), nickel(II), and copper(II) N,N'-disalicylidene-1,2-phenylenediamine complex for oxidation of 4-chloro-3methylphenol (PCMC) in Fenton-like advanced oxidation process than its counterpart homogenous catalyst of neat iron(III), nickel(II), and copper(II) N,N'-disalicylidene-1,2phenylenediamine complex [3]. 


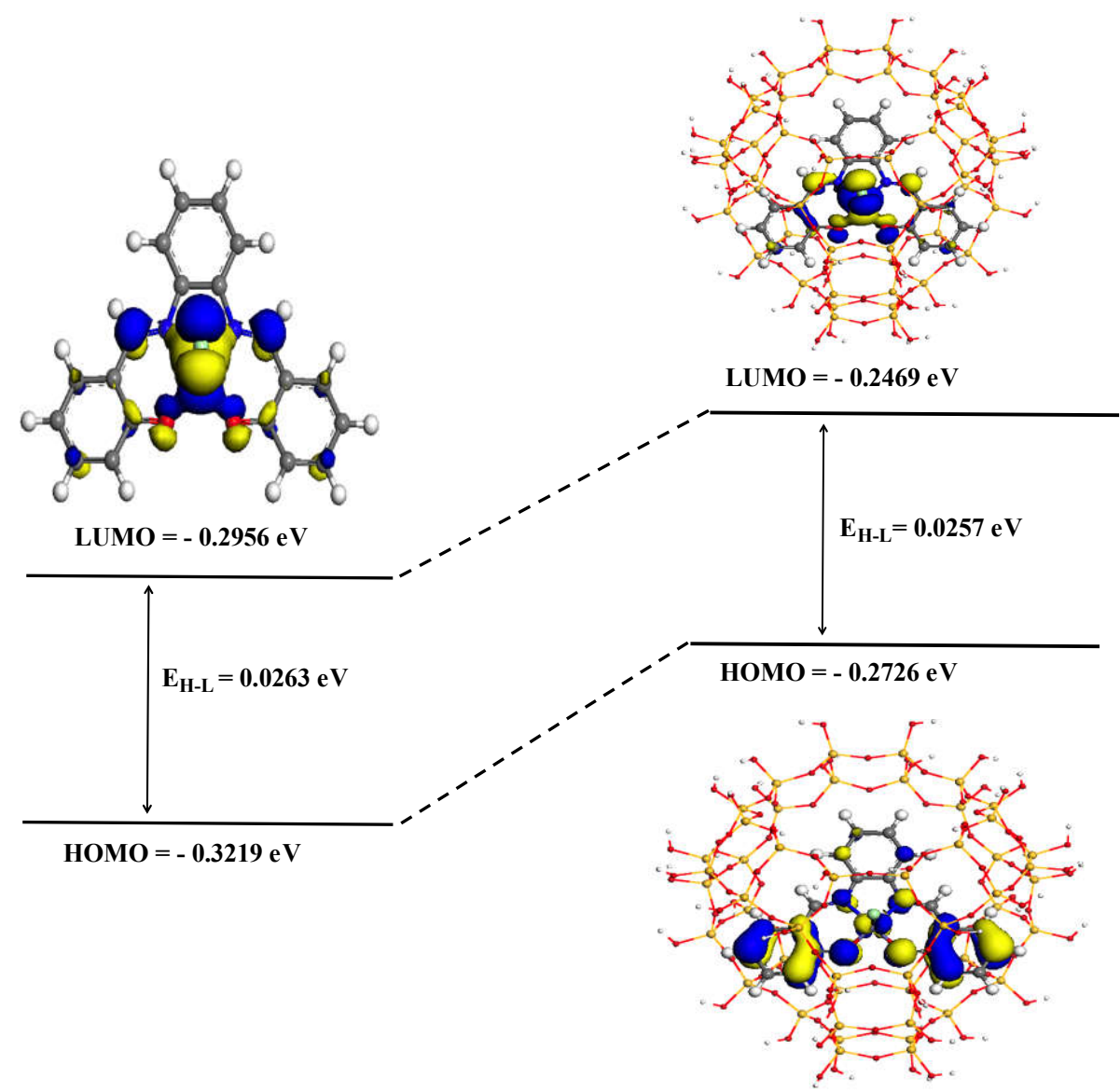

Fe(III)- Salophen Complex in Zeolite $Y$ cage

\section{Fe(III)- Salophen Complex}

Figure 3. Schematic representation of HOMO-LUMO gap change for iron(III)-Salophen metal complex based homogeneous and heterogeneous catalyst.

The change of the HOMO and LUMO energy orbitals of iron, nickel, and copper based metal complexes of homogeneous and heterogeneous catalytic system is either because of the influence of steric restriction or the counter ion in zeolite $\mathrm{Y}$ generated by the zeolite cage. The interaction of a host-guest molecule within the zeolite cage could be coordination effects, coulombic effects, and van der Waals forces [38]. The zeolite framework is made of aluminosilicate crystals having partial ionic character. This enables the charge distribution around the zeolite cage to generate a strong columbic field in the zeolite cavities. The fields created in the zeolite cage alter the energy level of the transition-metal complex and it enables the metal complex to change the HOMO-LUMO energy. 


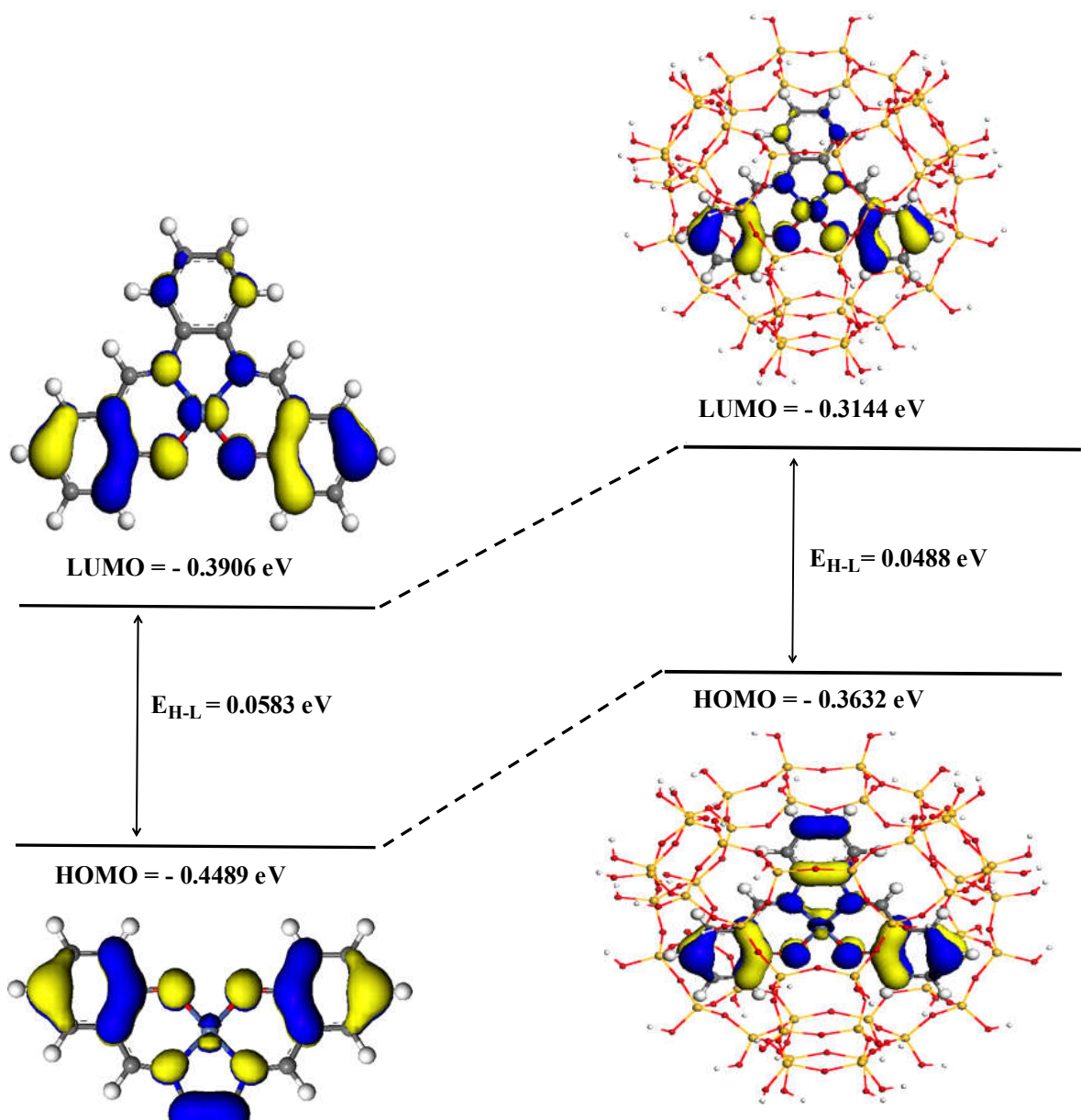

Ni(II)-Salophen Complex in Zeolite Y cage

\section{Ni(II)-Salophen Complex}

Figure 4. Schematic representation of HOMO-LUMO gap change for nickel(II)-Salophen metal complex based homogeneous and heterogeneous catalyst.

Furthermore, the presence of Si-O bonds in zeolite framework makes the zeolite to have a covalent character. Then the electrons have partially delocalized properties due to the presence of the partial covalent character in the aluminosilicate zeolite framework [22, 27]. Therefore, the geometrical as well as the electronic properties of the heterogeneous catalyst are likely to be influenced by the electron-electron repulsions between the electrons form the metal complex and the neighboring partially delocalized electrons in the zeolite cavities. The contribution of the coordination effects and van der Walls forces are small as compared to columbic effect because the coordination effects are produced by Lewis acid-base type interactions within the transitionmetal complexes and some parts of the zeolite framework. The van der Waals forces are also the 
weak electronic interactions generated in the zeolite cage then it contributes very weak forces to alter the HOMO-LUMO energy of the metal complexes.

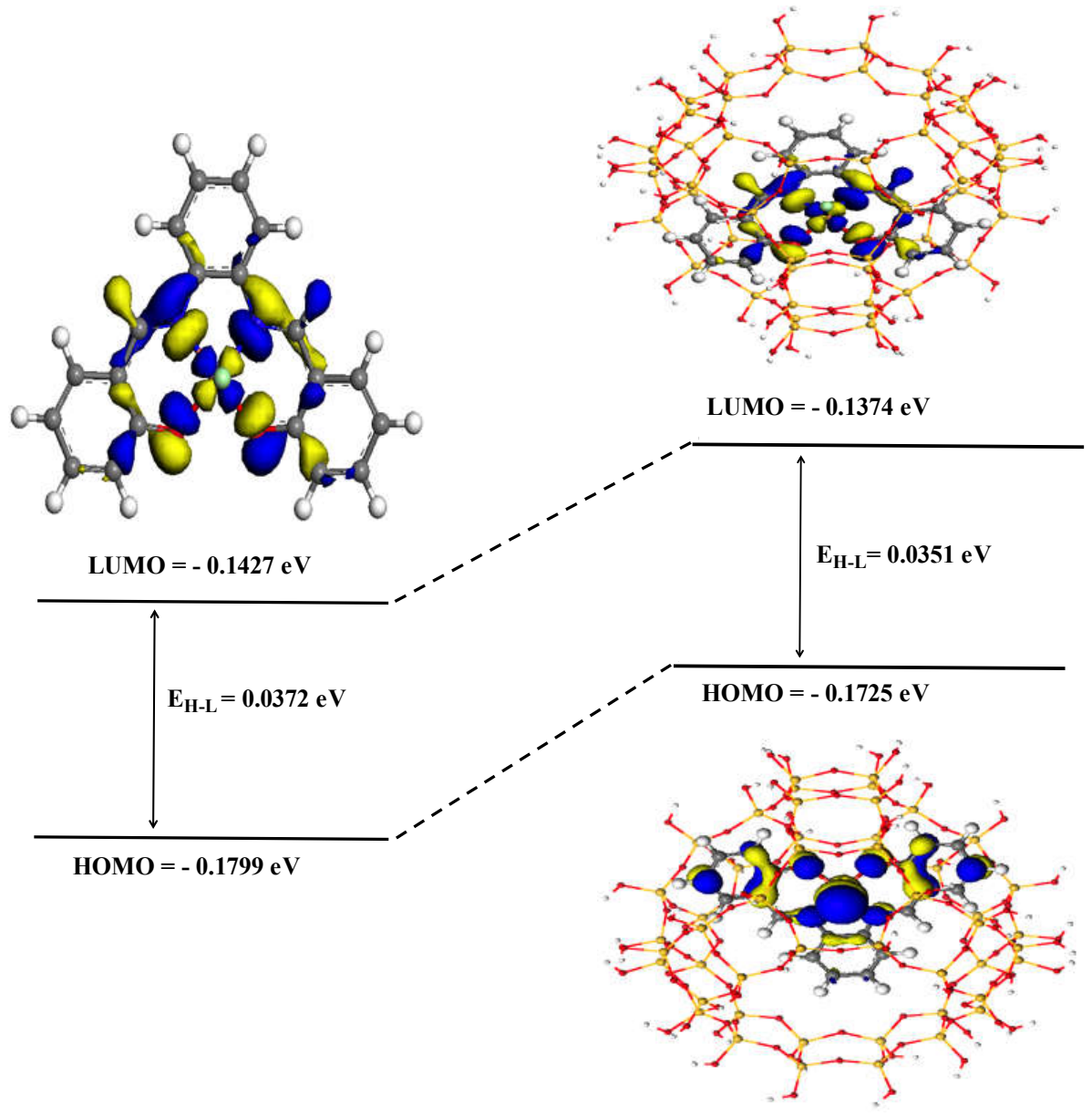

$\mathrm{Cu}(\mathrm{II})-$ Salophen Complex in Zeolite $\mathrm{Y}$ cage

\section{Cu(II)-Salophen Complex}

Figure 5. Schematic representation of HOMO-LUMO gap change for copper(II)-Salophen metal complex based homogeneous and heterogeneous catalyst.

The geometrical and electronic behaviors for the heterogeneous catalyst of $\mathrm{Fe}(\mathrm{III}), \mathrm{Ni}(\mathrm{II})$ and $\mathrm{Cu}$ (II) Salophen complexes reside in the zeolite $\mathrm{Y}$ cage is totally influenced by the zeolite matrix. Thus, the applying the DFT-Koopmans' theorem the global descriptors such as global hardness $(\eta)$ and softness (s) values for the homogeneous and heterogeneous catalyst were calculated and the results are depicted in Table 3. As observed from the table the heterogeneous catalyst has lower global hardness $(\eta)$ values and higher global softness values due to 
encapsulation into the zeolite cavities. Based on the principles of maximum hardness (MHP) and the minimum polarizability (MPP) [37, 39], (i.e. the hardness and polarizability (softness) measures the stability and reactivity of the metal complex, respectively), the most stable structure has maximum hardness and the less reactive species has minimum softness value. Therefore according to MH and MP principle, the zeolite encapsulated metal complexes or heterogeneous catalyst has minimum hardness values ( $\eta$ ) and maximum softness value (S) (Table 3). This implies that heterogeneous catalyst is comparatively less stable and more reactive than the neat complexes or homogeneous catalyst. On the other hand, heterogeneous catalysts have the lower value of electrophilicity $(\omega)$ and chemical potential $(\mu)$ as compared homogeneous catalyst. This suggested that once the metal complexes are encapsulated into zeolite super cage the influence of zeolite framework could alter the reactivity and stability of the metal complexes. Then, the heterogeneous catalyst of Fe(III), Ni(II) and $\mathrm{Cu}(\mathrm{II}) \mathrm{Salophen}$ complexes were destabilized and become more reactive on encapsulation compared to neat metal complexes or homogeneous catalyst.

Table 3. The calculated energy value of HOMO and LUMO (in eV), HOMO-LUMO gap ( $\Delta E_{\mathrm{H}-\mathrm{L}}$, in eV), chemical potential $(\mu$, in eV), global hardness $(\eta$, in eV) global electrophilicity $(\omega$, in eV) and global softness $(\mathrm{s}$, in $\mathrm{eV})$ for homogeneous and heterogeneous catalyst.

\begin{tabular}{|l|c|c|c|c|c|c|c|}
\hline Sample & $E_{\mathrm{HOMO}}$ & $E_{\mathrm{LUMO}}$ & $\Delta E_{\mathrm{H}-\mathrm{L}}$ & $\eta$ & $\boldsymbol{\mu}$ & $\boldsymbol{\omega}$ & $\boldsymbol{s}$ \\
\hline Fe(III)-Salophen complex & -0.3219 & -0.2956 & 0.0263 & 0.0132 & -0.3087 & 3.6246 & 38.0228 \\
\hline $\begin{array}{l}\text { Fe(III)-Salophen complex } \\
\text { in zeolite Y cage }\end{array}$ & -0.2726 & -0.2469 & 0.0257 & 0.0128 & -0.2597 & 2.6253 & 38.9105 \\
\hline Ni(II)-Salophen complex & -0.4489 & -0.3906 & 0.0583 & 0.0292 & -0.4197 & 3.0221 & 17.1527 \\
\hline $\begin{array}{l}\text { Ni(II)-Salophen complex } \\
\text { in zeolite Y cage }\end{array}$ & -0.3632 & -0.3144 & 0.0488 & 0.0244 & -0.3388 & 2.3522 & 20.4918 \\
\hline $\mathrm{Cu}$ (II)-Salophen complex & -0.1799 & -0.1427 & 0.0372 & 0.0186 & -0.1613 & 0.6994 & 26.8817 \\
\hline $\begin{array}{l}\text { Cu(II)-Salophen complex } \\
\text { in zeolite Y cage }\end{array}$ & -0.1725 & -0.1374 & 0.0351 & 0.0176 & -0.1549 & 0.6840 & 28.4900 \\
\hline
\end{tabular}

\section{CONCLUSIONS}

The iron(III), nickel(II) and copper(II)-Salophen complexes based heterogeneous catalysts were successfully modeled and calculated in the zeolite super cage. DFT geometrical and electronic parameters such as bond distance, bond angle, torsional angle, HOMO-LUMO energy gap are changed once the metal complex is encapsulated into the zeolite pore. Furthermore, the calculated value of the DFT-global descriptors like global hardness, global softness, electrophilicity and chemical potential computational results showed that the zeolite encapsulated metal complexes have higher reactivity and less stability as compared to the isolated metal complexes.

\section{ACKNOWLEDGMENTS}

Solomon Legese Hailu would like to thank Leather Industry Development Institute (LIDI), Government of Ethiopia, Addis Ababa, for full financial support for his $\mathrm{PhD}$ studies under Twinning Program between Leather Industry Development Institute (LIDI), Addis Ababa University (AAU) and CSIR-Central Leather Research Institute (CLRI).

\section{REFERENCES}

1. Heveling, J. Heterogeneous catalytic chemistry by example of industrial applications. $J$. Chem. Educ. 2012, 89, 1530-1536.

2. Kimura, E.; Sakonaka, A.; Machida R.; Kodama M.M. Novel nickel(II) complexes with doubly deprotonated dioxopentaamine macrocyclic ligands for uptake and activation of molecular oxygen. J. Am. Chem. Soc. 1982, 104, 4255-4257.

3. Hailu, S.L.; Nair, B.U.; Redi-Abshiro, M.; Aravindhan, R.; Isabel, D.; Tessema, M. 
Oxidation of 4-chloro-3-methylphenol using zeolite Y-encapsulated iron(III)-, nickel(II)-, and copper(II)-N,N'-disalicylidene-1,2-phenylenediamine complexes. Chin. J. Catal. 2016, 37, 135-145.

4. Sueli, M.D.; Renata, C.K.K.; Shirley, N.; Fernando, W. Encapsulation of Fe(III) and Cu(II) complexes in NaY zeolite. J. Colloid Interface Sci. 2004, 277, 138-145.

5. Herron, N. The Selective partial oxidation of alkanes using zeolite based catalysts. Phthalocyanine (PC) "Ship-in-Bottle" Species. J. Coord. Chem. 1988, 19, 25-38.

6. Robert, H.C. Deactivation in homogeneous transition metal catalysis: Causes, avoidance, and cure. Chem. Rev. 2015, 115, 127-150.

7. Sherborne, G.J.; Chapman, M.R.; Blacker, A.J.; Bourne, R.A.; Chamberlain, T.W.; Crossley. B.D.; Lucas, S.J.; McGowan, P.C; Newton, M.A.; Screen, T.E.O.; Thompson, P. Activation and deactivation of a robust immobilized $\mathrm{Cp}^{*}$ Ir-transfer hydrogenation catalyst: a multielement in situ x-ray absorption spectroscopy study. J. Am. Chem. Soc. 2015, 137, 4151-4157.

8. Gross, E.; Liu, G.H.C.; Toste, F.D.; Somorjai, G.A. Control of selectivity in heterogeneous catalysis by tuning nanoparticle properties and reactor residence time. Nature Chem. 2012, 4, 947-952.

9. Bailar, Jr. J.C. Heterogenizing of homogeneous catalysts. Catal Rev. 1974, 10, 17-36.

10. Abu-Reziqand, R.; Alper, H. Magnetically separable base catalysts: Heterogeneous catalysis vs. quasi-homogeneous catalysis. Appl. Sci. 2012, 2, 260-276.

11. Thomas, J.M.; Raja, R.; Lewis, D.W. Single site heterogeneous catalysis. Angew. Chem. Int. Ed. 2005, 44, 6456-6482.

12. Coperet, C.; Chabanas, M.; Saint-Arroman, R.P.; Basset. J.M. Homogeneous and heterogeneous catalysis: Bridging the gap through surface organometallic chemistry. Angew. Chem. Int. Ed. 2003, 42, 156-181.

13. Aravindhan, R.; Fathima, N.N.; Rao, J.R.; Nair, B.U. Wet oxidation of acid brown dye by hydrogen peroxide using heterogeneous catalyst Mn-salen-Y zeolite: a potential catalyst. $J$. Hazard. Mater. 2006, 138, 152-159.

14. Ayodele, O.B.; Lim, J.K.; Hameed, B.H. Pillared montmorillonite supported ferric oxalate as heterogeneous photo-Fenton catalyst for degradation of amoxicillin. Appl. Catal. A 2012 , 413, 301-309.

15. Kušić, H.; Koprivanac, N.; Selanec, I. Fe-exchanged zeolite as the effective heterogeneous Fenton-type catalyst for the organic pollutant minimization: UV irradiation assistance. Chemosphere 2006, 65, 65-73.

16. Dutta, B.; Jana, S.; Bera, R.; Saha, P.K.; Koner, S. Immobilization of copper Schiff base complexes in zeolite matrix: Preparation, characterization and catalytic study. Appl. Catal., A 2007, 318, 89-94.

17. Fathima, N.N.; Aravindhan, R.; Rao, J.R.; Nair. B.U. Dye house wastewater treatment through advanced oxidation process using $\mathrm{Cu}$-exchanged $\mathrm{Y}$ zeolite: A heterogeneous catalytic approach. Chemosphere 2008, 70, 1146-1151.

18. Figueiredo, H.; Silva, B.; Raposo, M.M.M.; Fonseca, A.M.; Neves, I.C.; Quintelas, C.; Tavares, T. Immobilization of Fe(III) complexes of pyridazine derivatives prepared from biosorbents supported on zeolites. Microporous Mesoporous Mater. 2008, 109, 163-171.

19. Liotta, L.F.; Gruttadauria, M.; Di Carlo, G.; Perrini, G.; Librando, V. Heterogeneous catalytic degradation of phenolic substrates: Catalysts activity. J. Hazard. Mater. 2009, 162, 588-606.

20. Kesraoui-Ouki, S.; Cheeseman, C.R.; Perry, R. Natural zeolite utilisation in pollution control: A review of applications to metals' effluents. J. Chem. Technol. Biotechnol. 1994, 59, 121-126.

21. Hernandez-Ramirez, O.; Holmes, S.M. Novel and modified materials for wastewater treatment applications. J. Mater. Chem. 2008, 18, 2751-2761. 
22. Hailu, S.L.; Nair, B.U.; Redi-Abshiro, M.; Aravindhan. R.; Isabel, D.; Tessema, M.; Experimental and computational studies on zeolite-Y encapsulated iron(III) and nickel(II) complexes containing mixed-ligands of 2,2-bipyridine and 1,10-phenanthroline. RSC Adv. 2015, 5, 88636-88645.

23. Wannakao, S.; Khongpracha, P.; Limtrakul, J. Density functional theory study of the carbonylene reaction of encapsulated formaldehyde in $\mathrm{Cu}(\mathrm{I}), \mathrm{Ag}(\mathrm{I})$, and $\mathrm{Au}(\mathrm{I})$ exchanged FAU zeolites. J. Phys. Chem. A 2011, 115, 12486-12492.

24. Jafarian, M.; Rashvand avei, M.; Khakali. M.; Gobal, F.; Rayati, S.; Mahjani, M.G. DFT and experimental study of the host-guest interactions effect on the structure, properties, and electro-catalytic activities of $\mathrm{N}_{2} \mathrm{O}_{2}-\mathrm{Ni}$ (II) Schiff-base complexes incorporated into zeolite. $J$. Phys. Chem. C 2012, 116, 18518-18532.

25. Hopmann, K.H.; Bayer, A. On the mechanism of iridium-catalyzed asymmetric hydrogenation of imines and alkenes: A theoretical study. Organometallics 2011, 30, 24832497.

26. Václavík, J.; Kuzma, M.; Přech, J.; Kačer, P. Asymmetric transfer hydrogenation of imines and ketones using chiral RuIICl ( $\eta 6-p-c y m e n e)[(\mathrm{S}, \mathrm{S})-\mathrm{N}-\mathrm{TsDPEN}]$ as a catalyst: A computational study. Organometallics 2011, 30, 4822-4829.

27. Ganesan, R.; Viswanathan, B. Redox properties of bis(8-hydroxyquinoline) manganese(II) encapsulated in various zeolites. J. Mol.Catal. A: Chem. 2004, 223, 21-29.

28. Bania, K.K.; Bharali, D.; Viswanathan, B.; Deka, R.C. Enhanced catalytic activity of zeolite encapsulated $\mathrm{Fe}(\mathrm{III})$-Schiff-base complexes for oxidative coupling of 2-napthol. Inorg. Chem. 2012, 51, 1657-1674.

29. Ozgur, A. FT-IR, Raman and DFT studies on the vibrational spectra of 2,2bis(aminoethoxy) propane. Bull. Chem. Soc. Ethiop. 2016, 30, 147-151.

30. Ye, Z.; Ting, L.; Qiwen, T. Theoretical study on electronic structures and spectroscopy of triarylborane substituted by thiophene. Bull. Chem. Soc. Ethiop. 2009, 23, 77-83.

31. Özgür, A.; Cemal, P.; Mustafa, Ş. NMR spectroscopic study and DFT calculations of vibrational analyses, giao NMR shieldings and $1 \mathrm{jch}, 1 \mathrm{jcc}$ spin-spin coupling constants of 1,7-diaminoheptane. Bull. Chem. Soc. Ethiop. 2009, 23, 85-96.

32. Han, L.H.; Zhang, C.R.; Zhe, J.W.; Jin, N.Z.; Shen, Y.L.; Wang, W.; Gong, J.J.; Chen, Y.H.; Liu, Z.J. Understanding the electronic structures and absorption properties of porphyrin sensitizers YD2 and YD2-o-C8 for dye-sensitized solar cells. Int. J. Mol. Sci. 2013, 14, 20171-20188.

33. Mihaylov, T.; Trendafilova, N.; Kostova, I.; Georgieva, I.; Bauer, G. DFT modeling and spectroscopic study of metal-ligand bonding in $\mathrm{La}(\mathrm{III})$ complex of coumarin-3-carboxylic acid. Chem. Phys. 2006, 327, 209-219.

34. Ganesan, R.; Viswanathan, B. Physicochemical and catalytic properties of copper ethylenediamine complex encapsulated in various zeolites. J. Phys. Chem. B 2004, 108, $7102-7114$.

35. Ganesan, R.; Viswanathan, B. Redox properties of bis(8-hydroxyquinoline)manganese(II) encapsulated in various zeolites. J. Mol. Catal. A: Chem. 2004, 223, 21-29.

36. Koopmans, T. Ordering of wave functions and eigenenergies to the individual electrons of an atom. Physica 1933, 1, 104-113.

37. Parr, R.G.; Chattaraj, P.K. Principle of maximum hardness. J. Am. Chem. Soc. 1991, 113, $1854-1855$

38. Zicovichwilson, C.M.; Corma, A.; Viruela, P. Electronic confinement of molecules in microscopic pores. A new concept, which contributes to the explanation of the catalytic activity of zeolites. J. Phys. Chem. 1994, 98, 10863-10870.

39. Chattaraj, P.K.; Liu, G.H.; Parr, R.G. The maximum hardness principle in the GyftopoulosHatsopoulos three-level model for an atomic or molecular species and its positive and negative ions. Chem. Phys. Lett. 1995, 237, 171-176. 